\title{
Energetic and developmental costs of mounting an immune response in greenfinches (Carduelis chloris)
}

\begin{abstract}
It is assumed that there is a trade-off between the costs allocated to mounting an immune defence and those allocated to costly functions such as breeding and moulting. The physiological basis for this is that mounting an immune response to pathogen challenge has energetic and/or nutrient costs which may interfere with metabolic processes of the challenged individual. If the energetic costs of mounting an immune response are not too high, animals may face such costs by increasing their acquisition of food energy, suggesting that limited nutrients may be responsible for the costs of immune defence. We assessed the energetic and developmental costs of mounting an immune response in an experiment in captivity with first-year greenfinches (Carduelis chloris) challenged with sheep red blood cells and Brucella abortus. Antibody production against both antigens increased the daily energy expenditure $(4.7 \%)$ of immunechallenged birds relative to control birds, although the difference was non-significant. We estimated that the maximum effect size supported by the data would be $9.9 \%$ higher in immune-challenged birds relative to control birds. We plucked the two outermost rectrices of each bird to assess the effects of the immune challenge on growth of the regenerated feathers. The immune challenge had no significant effect on the length of the regenerated rectrices. However, these feathers were more asymmetric in length in immune-challenged birds than in control birds. Although first-year male greenfinches paid a relatively low energetic cost when mounting an immune response, we suggest that immune-challenged
\end{abstract}

\footnotetext{
J. A. Amat (\&) E. Aguilera

Estacion Biologica de Donana,

Consejo Superior de Investigaciones Cientıficas,

Apartado 1056, 41080 Sevilla, Spain

E-mail: amat@ebd.csic.es

Tel.: +34-954-232340

Fax: +34-954-621125

G. H. Visser

Research Group Behavioural Ecology and Centre for Isotope Research, University of Groningen, P.O. Box 14, 9750 AA Haren, The Netherlands
}

individuals may have paid some costs over the long term based on the increased fluctuating asymmetry in the developing feathers.

Keywords Carduelis chloris $₫$ Energetic costs $\Vdash$

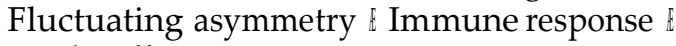

Trade-offs

Introduction

It is assumed that there is a trade-off between the costs allocated to immune defence and those allocated to costly organismal functions such as breeding or moult (Deerenberg et al. 1997; Apanius 1998; Raberg et al. 1998; Schmid-Hempel 2003; Sanz et al. 2004). The physiological basis for this is that mounting an immune response to pathogen challenge has energetic and/or nutrient costs (Demas et al. 1997; Wakelin 1997; Buttgereit et al. 2000; Ots et al. 2001; Martin et al. 2003; Klasing 2004; but see Svensson et al. 1998) that may interfere with the metabolic processes of the challenged individual (Kilgore et al. 1988; Nelson and Demas 1996; Sheldon and Verhulst 1996; Lochmiller and Deerenberg 2000).

Previous studies on the energetic costs of mounting an immune response in birds have obtained conflicting results. Thus, while in some cases an increase in the basal metabolism of immune-challenged individuals was reported (Ots et al. 2001; Martin et al. 2003; Eraud et al. 2005), no such effect was found in other studies (Svensson et al. 1998; Fair and Ricklefs 2002; Horak et al. 2003). Horak et al. (2003) surmised that this discrepancy may be due in part to methodological differences, since two of the studies that did not find an increase in energy expenditure in immune-challenged individuals were conducted in captivity, where food and water were provided ad libitum. However, other studies with captive individuals also found a greater energy expenditure in immune-challenged birds (Martin et al. 2003; Eraud et al. 2005). If the energetic costs of 

mounting an immune response are not too high, animals may face such costs either by increasing their food intake or by reducing the energy allocated to other functions such as locomotion, (Yorinks and Atkinson 2000; Bonneaud et al. 2003; Horak et al. 2003; Lindstrom et al. 2003). In the last case there may not be measurable differences in energy expenditure between immunechallenged and non-challenged individuals (Derting and Compton 2003). This indicates that nutrient availability may mediate the costs of immune defence (Norris and Evans 2000; Zuk and Stoehr 2002).

Therefore, nutrient costs may be as important as energetic costs in mounting an immune response. Because both energy and nutrients are usually limited, there may be a reallocation of resources and, consequently, trade-offs between physiological activities (Wilkeski and Ricklefs 2001; Monaghan 2004). The consequences of these trade-offs for immune-challenged individuals may be expressed on long-term fitness, and examples of such costs include increased fluctuating asymmetry (Fair et al. 1999; Fair and Myers 2002; Whitaker and Fair 2002; but see Civantos et al. 2005). Fluctuating asymmetry is defined as small random deviations from perfect bilaterally symmetrical morphological traits. This parameter may be a good indicator of an individual's ability to cope with physiological stress because it indicates developmental stability (Van Valen 1962; Palmer and Strobeck 1986; Møller and Swaddle 1997). Fluctuating asymmetry may have fitness costs if it affects sexually selected traits (e.g. Lagesen and Folstad 1998) or morphological traits related to escape performance from predators (e.g. Galeotti et al. 2005).

In the investigation reported here we focus on the energetic and developmental costs of mounting an immune response in greenfinches (Carduelis chloris). A previous study on this species found a low but non-significant increase in energy expenditure of immune-challenged individuals (Horak et al. 2003), as we also report in our study. However, our immune-challenged greenfinches could have paid some costs over the long term based on our observations of increased fluctuating asymmetry in developing feathers.

\section{Methods}

We captured under licence first-year male greenfinches with mist nets between 16 October and 1 November 2000 near Seville (SW Spain). The birds were housed in outdoor aviaries, where food [a mixture of canary seeds (Phalaris canariensis, 46\%), hemp seeds (Cannabis sativa, 18\%), oat seeds (Avena sativa, 9\%), niger seeds (Guizotia abyssinica, 9\%), turnip rape seeds (Brassica rapa, 9\%), and sunflower seeds (Helianthus annuus, 9\%)] and water were provided ad libitum.

On 4 December, 9 days before the birds were injected with either antigens or a phosphate-buffered saline solution (PBS), 44 birds were randomly assigned into four groups (11 birds per group), and each group was housed in an outdoor aviary (3-3-2 $\mathrm{m}$ high). On 11 December, the birds were weighed with a portable Sartorius balance to the nearest $0.1 \mathrm{~g}$ and their flight feathers examined. Those individuals that had not lost any flight feathers during captivity were housed in individual cages $(30-20-30 \mathrm{~cm}$ high) inside an outdoor aviary to study the costs of mounting an immune response. By placing the birds in these small cages their movements were limited, so we minimized potential differences in daily energy expenditure due to a reduction in the activity of immune-challenged birds (Kilgore et al. 1988; Yorinks and Atkinson 2000; Horak et al. 2003; Lindstrom et al. 2003). We also plucked the two outermost rectrices (R6) of each bird to measure the effects of immunology on the growth of the regenerated feathers. The diet of the birds in the individual cages was the same as that of the birds in the aviaries.

On 14 December, the birds were weighed and injected with either antigens (immune challenged group, ICG) or PBS (control group, CG). We utilized two types of antigens, sheep red blood cells (SRBC; Catalog no. R3378, Sigma-Aldrich, St Louis, Mo.) and Brucella abortus agglutination concentrate (BA; catalog no. BF502, Bifa-kit SL, Madrid) to challenge the immune system of the birds. Each immune-challenged bird received both antigens. These antigens have been shown to stimulate T-dependent (SRBC) and T-independent (BA) humoral responses (Higgins 1996). This combination of antigens has been used before to measure the two components of the avian humoral response (see Dabbert et al. 1997; Birkhead et al. 1998). Birds of the ICG group received an intra-muscular injection of $25 \mathbf{1 l}$ of BA and an intra-peritoneal injection of $2 \%$ SRBC suspended in 10011 of PBS; birds of the CG group received PBS, both intra-muscular $(25$ ll) and intra-peritoneal (100 11) injections.

We used haemoagglutination assays in 96-well microplates to measure antibody titres to SRBC (Wegmann and Smithies 1966). Briefly, 2011 of heat-inactivated plasma (heating at $56^{\circ} \mathrm{C}$ for $30 \mathrm{~min}$ ) was added to $20 \mathrm{1l}$ PBS in the first well of a plate; serial dilutions in PBS $(1: 2,1: 4,1: 8$, etc) were then carried out in the wells, followed by the addition of 2011 of a $2 \%$ suspension of SRBC to each well. The plates were kept at ambient temperature and examined for agglutination $2 \mathrm{~h}$ after they were prepared. Antibody titres to BA were measured by agglutination assays (Munns and Lamont 1991). For the BA assays we followed the same protocol as for haemoagglutination assays but used a BA agglutination concentrate instead of the SRBC suspension and the plates were examined for agglutination after $24 \mathrm{~h}$ according to the recommendations of the manufacturer. Antibody responses to each antigen were estimated as the log of the reciprocal of the last dilution that showed agglutination.

On 19 December (day 5 after injection of either PBS or antigens) we recorded the body masses of the 
greenfinches and injected them intra-peritoneally with a dose of $0.1 \mathrm{ml}$ doubly labelled water (DLW). The DLW dose was administered using $0.5-\mathrm{ml}$ calibrated insulin syringes. We applied the single-sample method to determine daily energy expenditure (Webster and Weathers 1989). Following the DLW injection, all except seven birds were returned to their individual cages to the aviary. From the seven individuals not returned to their cages we collected after $1 \mathrm{~h}$, the time required for isotopes to equilibrate in the body fluids, an initial blood sample in six microcapillary tubes (each filled with 1511 blood) that were immediately flame sealed with a propane torch. Approximately $24 \mathrm{~h}$ later (day 6) all of the birds were re-weighed, and a final blood sample was taken from all birds. Determinations (in triplicate) of $\left[{ }^{2} \mathrm{H} /{ }^{1} \mathrm{H}\right]$ and $\left[{ }^{8} \mathrm{O} /{ }^{16} \mathrm{O}\right]$ isotope ratios were carried out using isotope ratio mass spectrometry following the analytical procedures described by Visser and Schekkerman (1999). The amount of body water was then calculated for the seven birds in which equilibration blood samples had been collected $1 \mathrm{~h}$ after injection, based on the principle of $\left[{ }^{18} \mathrm{O}\right]$ dilution (plateau method; Speakman 1997). The calculated amount of body water was not significantly related to body mass $(p=0.72$, $n=7)$, enabling us to use the average value $(65.2 \%)$ for all birds. Using this value, we calculated the $\left[{ }^{2} \mathrm{H}\right]$ and $\left[{ }^{18} \mathrm{O}\right]$ isotope enrichments for all birds $1 \mathrm{~h}$ after injection. The rate of $\mathrm{CO}_{2}$ production was calculated with Equation 35 of Lifson and McClintock (1966) using both the calculated individual-specific "initial" and measured "final" isotope concentrations and the populationspecific "background" concentration (based on samples taken from three birds prior to the experiment). Lastly, the field metabolic rate (FMR) was calculated from the rates of $\mathrm{CO}_{2}$ production using a conversion factor of $22 \mathrm{~kJ} \mathrm{l}^{-1}$ (Gessaman and Nagy 1988). We estimated FMR on day 6 postimmunization because the maximum antibody response was assumed to be then at its peak level (see Svensson et al. 1998).

The birds were then returned to their original aviaries until 26 December, when the lengths of the regenerated tail feathers were measured with a ruler to the nearest $0.5 \mathrm{~mm}$, and the greenfinches were then released at the site of capture. Measurements were always made by one of us (E.A.). Fluctuating asymmetry was estimated for these feathers as the absolute differences between the numerical values of the left and right measurements (e.g. Palmer and Strobeck 1986). We could not estimate fluctuating asymmetry in all birds because three birds died (two in the IGC group and one in the CG group) between 20-26 December.

Because these birds were also being used in a simultaneous experiment on the effects of carotenoid supplementation on immunology (Aguilera and Amat unpublished), we randomly assigned half of the carotenoid-supplemented birds and half of the non-supplemented birds to one of two groups according to whether they were injected with antigens or with PBS.
Statistical analyses

As FMR correlated positively with the body mass of greenfinches $(\mathrm{r}=0.62, \mathrm{n}=29, \mathrm{p}<0.001)$, we used masscorrected FMR in subsequent comparisons. Supplementation with carotenoids had no significant effect on either FMR $\left(\mathrm{F}_{1,},{ }_{27}=1.62, \mathrm{p}=0.21\right)$ or fluctuating asymmetry of the tail feathers $\left(\mathrm{F}_{1,25}=0.38, \mathrm{p}=0.54\right)$. Therefore, we combined both groups in the following analyses.

Differences in FMR, length of feathers and asymmetry in feather length between immune-challenged and control birds were assessed using Student's independent t-tests or Mann-Whitney U-test, depending on whether the data met the assumption of homogeneity of variances. We tested whether there were temporal variations in the body masses of greenfinches during the experimental treatment using analysis of variance (ANOVA) for repeated measures.

We conducted all statistical tests using STATISTICA (StatSoft, Tulsa, Okla. 2001). Mean values are presented with \pm 1 standard deviation (SD) unless otherwise stated.

Results

Metabolic costs of mounting an immune response

For unknown reasons, none of the immune-challenged birds showed antibody responses against SRBC, but antibody responses to BA were observed in 12 out of 16 individuals injected with antigens. None of the birds of the control group exhibited antibody responses to BA (Aguilera and Amat, unpublished).

Six days following the injection of either antigen or PBS, the FMR of immune-challenged birds was, on average, $0.1 \mathrm{~kJ}^{\text {day }}{ }^{-1} \mathrm{~g}^{-1}$ higher than that of the control birds $\left[2.44 \pm 0.17(\mathrm{n}=16)\right.$ vs. $2.33 \pm 0.18 \mathrm{~kJ}^{\mathrm{day}}{ }^{-1} \mathrm{~g}^{-1}$ $(n=13)$, respectively; Fig. 1]. This statistically non-significant value $\left(\mathrm{t}_{27}=1.52, \mathrm{p}=0.14\right)$ represents a $4.7 \%$ elevation in the FMR of immune-challenged birds. This lack of a significant effect of the immune challenge on energy expenditure persisted when we eliminated from the comparison the four birds injected with antigens that did not show an antibody response to $\mathrm{BA}\left(\mathrm{t}_{23}=1.41\right.$, $\mathrm{p}=0.17)$. Nevertheless, as pointed out by Svensson et al. (1998), because all metabolic processes have an energetic cost, the important question is just where is the ceiling of that cost. The upper limit of the $95 \%$ confidence interval of the difference between treatment groups gives an estimate of the maximum effect size that is actually supported by our data (Colegrave and Ruxton 2003). This estimate was $0.23 \mathrm{~kJ} \mathrm{day}^{-1} \mathrm{~g}^{-1}$, which is equivalent to a $9.9 \%$ elevation in FMR. Consequently, we can reject, at the $2.5 \%$ level, the hypothesis that the energetic cost of mounting an immune response in our experimental birds was greater than that value. 


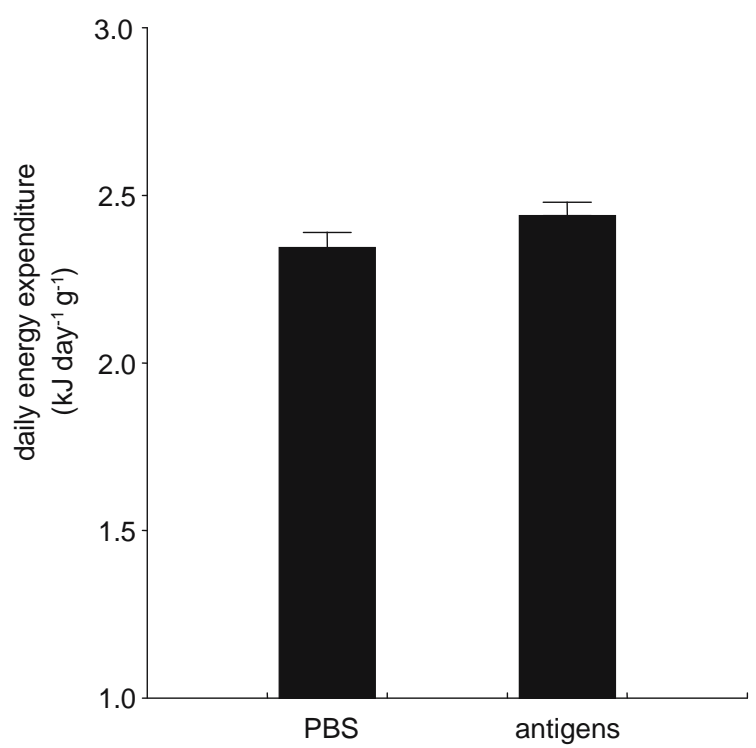

Fig. 1 Mean daily energy expenditure $(+1 \mathrm{SE})$ of first-year male greenfinches (Carduelis chloris) injected with antigens [sheep red blood cells (SRBC) and Brucella abortus (BA), $n=16]$, or with phosphate-buffered saline solution (PBS, $n=13$ )

Effects of immune challenge on feather growth and body mass

The immune challenge had no significant effect on the length of regenerated rectrices 15 days after the original ones had been pulled out [immune-challenged birds: $11.8 \pm 3.6 \mathrm{~mm} \quad(\mathrm{n}=14)$; control birds: $13.7 \pm 3.9 \mathrm{~mm}$ $\left.(\mathrm{n}=13) ; \mathrm{t}_{25}=-1.25, \mathrm{p}=0.22\right)$. However, these feathers were more asymmetric in length in the immune-challenged birds than in the control birds (Fig. 2; MannWhitney U-test, $\mathrm{z}=2.28, \mathrm{p}=0.02$ ).

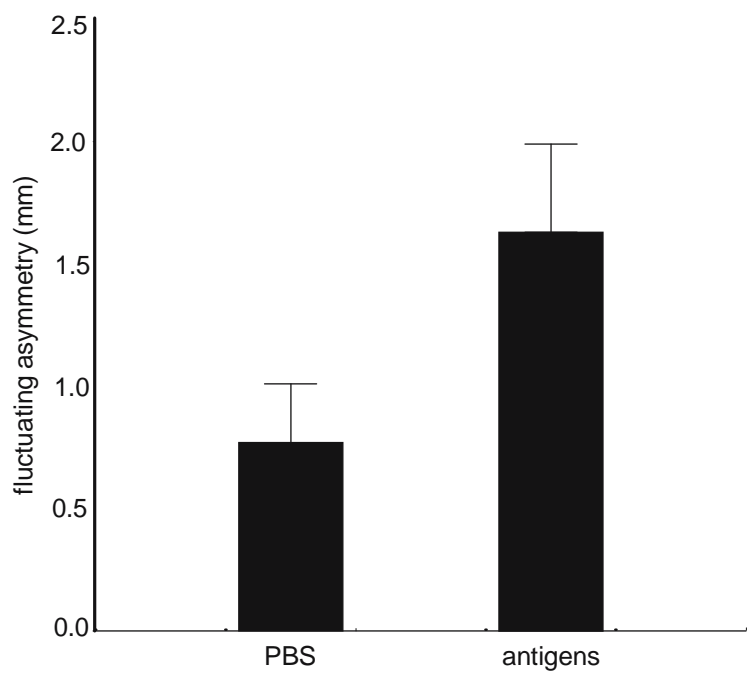

Fig. 2 Fluctuating asymmetry in the length of the outermost tail feathers (means $+1 \mathrm{SE}$ ) of first-year male greenfinches injected with antigens (SRBC and BA, $n=14)$ or with PBS $(n=13)$. Fluctuating asymmetry was estimated as the absolute differences between the lengths of the left and right tail feathers
There were no temporal changes in the body mass of greenfinches in ICG and CG during the study (Fig. 3; ANOVA for repeated measures tested by immunological treatment - time interaction; treatment effect: $F_{2}$, $\left.{ }_{56}=0.02, \mathrm{p}=0.984\right)$. In addition, the interaction between time and immunological treatment had no effect on body mass $\left(\mathrm{F}_{2,}{ }_{56}=0.46, \mathrm{p}=0.639\right)$.

\section{Discussion}

The results of our study indicated that mounting a humoral immune response had a small energetic cost for first-year male greenfinches. While we were unable to detect an antibody response to SRBC in our greenfinches, individuals of the same species have been reported to exhibit an antibody response to the same antigen (Horak et al. 2003). The different results may be due to the different SRBC concentrations injected into greenfinches in the two studies (see Glick et al. 1981). In our study, $75 \%$ of the birds showed antibody responses to BA. The lack of differences in FMR between the control and experimental birds persisted when we eliminated from the comparison those birds injected with antigen that did not exhibit antibody response. Similar results - the absence of significant increases in energy expenditure between the control and experimental birds - have been reported in other studies in which the administration of antigens elicited antibody responses (Svensson et al. 1998; Horak et al. 2003), although the immunized birds of these other studies also had slightly higher metabolic rates than the control ones, as in the present study.

We estimated that the upper limit of FMR to mount an immune response was $9.9 \%$, although the mean value was lower $(4.7 \%)$. Since the difference in FMR between

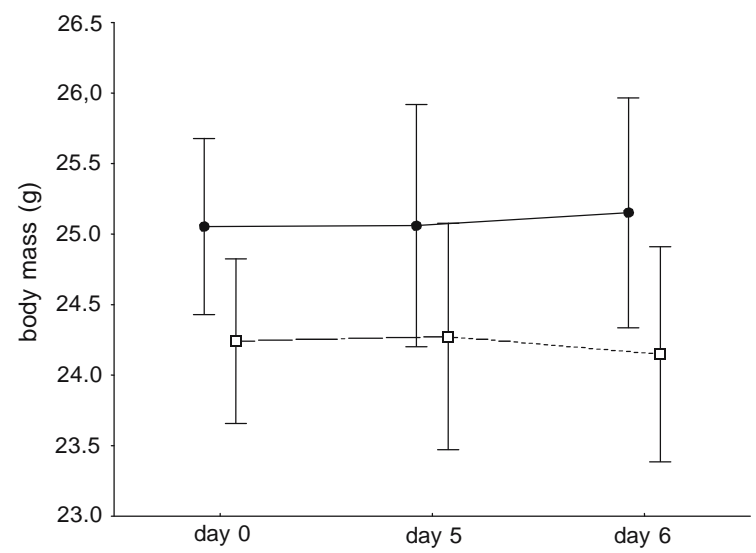

Fig. 3 Mean body masses ( $\pm 95 \%$ confidence intervals) of firstyear male greenfinches in the immunized-challenged (open symbols, $\mathrm{n}=16$ ) and control (closed symbols, $\mathrm{n}=14$ ) groups on day 0 (when they were injected with either PBS or antigens), day 5 postimmunization (when they were injected with doubly-labelled water) and day 6 postimmunization (when they were bled for estimation of daily energy expenditure) 
the experimental and control group was not significant, an increase in sample size would make the upper confidence interval even lower (see Svensson et al. 1998). This suggests that the energetic costs of mounting humoral immune responses are small, especially when compared with the overall costs of other physiological processes (Svensson et al. 1998). As this increase has been observed to be moderate $(<10 \%)$ even in other studies that found a significant increase in BMR in immune-challenged birds relative to controls (Ots et al. 2001; Eraud et al. 2005), it may be that the energetic costs of mounting a humoral immune response are not high enough to elicit trade-offs with other physiological processes.

Although we found that using the immune system was not too costly for greenfinches in energetic terms, individuals also have to pay other types of costs for immunity, such as those allocated to both the development and maintenance of the immune system (Klasing 2004). There are seasonal changes in immune function, and mechanisms have evolved which allow animals to anticipate immunologically challenging conditions (Nelson and Demas 1996). It remains to be elucidated whether there are trade-offs between the resources that animals allocate to develop, maintain and use the immune system. This type of trade-off could explain the relatively low energy allocated to mounting an immune response if the immune challenge coincides with periods when animals are allocating more resources to enhance the immune function (for example, because they develop a larger spleen; but see Derting and Compton 2003).

Some seasonal biological functions (breeding, moulting, among others) are considerably more costly in energetic terms than mounting an immune response, suggesting that birds could pay more energy, at least during some parts of the year, to face an immune challenge. Another possibility in addition to trade-offs among functions in the immune system itself to explain why birds do not pay more to face an immune challenge is that a stronger immune response incurs a greater risk of immunopathology (Nelson and Demas 1996; Zuk and Stoehr 2002).

Energy, however, is not the only resource that may affect trade-offs between immune response and other physiological functions, and specific nutrients, such as proteins, may also be involved in such trade-offs (Zuk and Stoehr 2002; Klasing 2004). It is likely that up-regulation of the immune response could have caused an asymmetrical development of the tail feathers in our study (see Whitaker and Fair 2002), suggesting that activation of the immune system may decrease the resources necessary for feather growth (Sanz et al. 2004). Our estimation of fluctuating asymmetry may be conservative because the re-grown rectrices were measured before they were fully grown, and some authors have shown that fluctuating asymmetry remains similar or even increases during ontogeny (Campo et al. 2005; Ivanovic and Kalecic 2005). In addition, fluctuating asymmetry increases with feather length (Fair et al. 1999).
On the basis of the present results we conclude that the cost associated with the immune response was an increase in fluctuating asymmetry in developing tail feathers. Previous studies have also found an increase in fluctuating asymmetry in developing feathers in chicks when there was an immune challenge, both in precocial (Fair and Ricklefs 2002) and altricial species (Fair and Myers 2002; Whitaker and Fair 2002), suggesting that this negative effect may occur across several avian taxa. Because tail feathers are important during flight, this increase in asymmetry could impair flight performance and have negative effects on escape behaviour from predators (e.g. Thomas 1993; Galeotti et al. 2005). Also, because females use the symmetry of morphological traits for mate choice (Swaddle 1996), the reproductive success of more asymmetrical males could be decreased.

In conclusion, although the energetic costs of mounting a humoral immune response in first-year greenfinches were low, immune-challenged individuals could have paid some costs over the long term due to increased fluctuating asymmetry in developing feathers. As in other studies that have assessed the energetic costs of mounting an immune response, we used nonpathogenetic antigens. It remains to be shown whether the energetic costs of mounting an immune response to these nonpathogenic antigens is equivalent to those of an immune challenge by more acute pathogens.

Acknowledgments We thank Rocio Ru1z, Nico Varo and Manuel Vazquez for field assistance and taking care of birds in captivity. Consejerı de Medio Ambiente (Junta de Andalucia) gave permission to capture the birds and carry out the experiments. Financial support was received from Spanish DGESIC (grant PB98-0494-C02-01). The manuscript benefited from the comments of two anonymous referees on an earlier version.

\section{References}

Apanius V (1998) Stress and immune defense. Adv Study Behav 27:133-153

Birkhead TR, Fletcher F, Pellat EJ (1998) Sexual selection in the zebra finch, Taenopygia guttata: condition, sex traits and immune capacity. Behav Ecol Sociobiol 44:179-191

Bonneaud C, Mazuc J, Gonzalez G, Haussy C, Chastel O, Faivre B, Sorci G (2003) Assessing the cost of mounting an immune response. Am Nat 161:367-379

Buttgereit F, Burmester G-R Brand MD (2000) Bioenergetics of immune functions: fundamental and therapeutic aspects. Immunol Today 21:192-199

Campo JL, Gil MG, Davila SG, Munoz I (2005) Estimation of heritability for fluctuating asymmetry in chickens by restricted maximum likelihood. Effects of age and sex. Poultry Sci 84:1689-1697

Civantos E, Forsman A, Ahnesjo J (2005) Developmental instability and immune function in colour polymorphic pygmy grasshoppers. Evol Ecol 19:1-14

Colegrave N, Ruxton GD (2003) Confidence intervals are a more useful complement to nonsignificant tests than are power calculations. Behav Ecol 14:446-447

Dabbert CB, Lochmiller RL, Teeter RG (1997) Effects of acute thermal stress on the immune system of the northern bobwhite (Colinus virginianus). Auk 114:103-109 
Deerenberg C, Apanius V, Daan S, Bos N (1997) Reproductive effort decreases antibody responsiveness. Proc $\mathrm{R}$ Soc Lond [Biol] 264:1021-1029

Demas G, Chefer V, Talan M, Nelson R (1997) Metabolic costs of mounting an antigen-stimulated immune response in adult and aged C57BL/6J mice. Am J Physiol 273:R1631-R1637

Derting TL, Compton S (2003) Immune response, not immune maintenance, is energetically costly in wild white-footed mice (Peromyscus leucopus). Physiol Biochem Zool 76:744-752

Eraud C, Duriez O, Chastel O, Faivre B (2005) The energetic cost of humoral immunity in the collared dove, Streptopelia decaocto: is the magnitude sufficient to force energy-based tradeoffs? Funct Ecol 19:110-118

Fair JM, Myers OB (2002) The ecological and physiological costs of lead shot and immunological challenge to developing western bluebirds. Ecotoxicol 11:199-208

Fair JM, Ricklefs RE (2002) Physiological, growth, and immune responses of Japanese quail chicks to the multiple stressors of immunological challenge and lead shot. Arch Environ Cont Toxicol 42:77-87

Fair JM, Hansen ES, Ricklefs RE (1999) Growth, developmental stability and immune response in juvenile Japanese quails (Coturnix coturnix japonica). Proc R Soc Lond [Biol] 266:17351742

Galeotti P, Sacchi R, Vicario V (2005) Fluctuating asymmetry in body traits increases predation risks: tawny owl selection against asymmetric woodmice. Evol Ecol 19:405-418

Gessaman JA, Nagy KA (1988) Energy metabolism: errors in gasexchange conversion factors. Physiol Zool 61:507-513

Glick B, Day EJ, Thompson D (1981) Calorie-protein deficiencies and the immune response of the chicken. I. Humoral immunity. Poultry Sci 60:2494-2500

Higgins DA (1996) Comparative immunology of avian species. In: Davison TF, Morris TR, Payne LN (eds) Poultry immunology. Abingdon, Carfax, pp 149-205

Horak P, Saks L, Ots I, Kullissaar T, Kollist H, Zilmer M (2003) Physiological effects of immune challenge in captive greenfinches (Carduelis chloris). Can J Zool 81:371-379

Ivanovic A, Kalezic ML (2005) Facultative paedomorphosis and developmental stability in European newts (Triturus spp., Samandridae): onthogenetic aspect. Ital J Zool 72:265-270

Kilgore MW, Stewart GL, Smatresk NJ (1988) Oxygen uptake in mice infected with Trichinella spiralis. J Parasitol 74:721-724

Klasing KC (2004) The cost of immunity. Acta Zool Sinica 50:961969

Lagesen K, Folstad I (1998) Antler asymmetry and immunity in reindeer. Behav Ecol Sociobiol 44:135-142

Lifson N, McClintock F (1966) Theory of use of the turnover rates of body water for measuring energy and material balance. J Theor Bin 12:46-74

Lindstrom KM, van der Veen IT, Legault BA, Lundstrom JO (2003) Activity and predator escape performance of common greenfinches Carduelis chloris infected with Sinbis virus. Ardea 91:103-111

Lochmiller R, Deerenberg C (2000) Trade-offs in evolutionary immunology: just what is the cost of immunity? Oikos 88:87-98

Martin II LB, Scheuerlein A, Wikelski M (2003) Immune activity elevates energy expenditure of house sparrows: a link between direct and indirect costs? Proc R Soc Lond [Biol] 270:153-158

Møller AP, Swaddle JP (1997) Asymmetry, developmental stability, and evolution. Oxford University Press, Oxford
Monaghan P (2004) Resource allocation and life history strategies in birds. Acta Zool Sinica 50:942-947

Munns PL, Lamont SJ (1991) Effects of age and immunization interval on anamnestic response to T-cell-dependent and T-cellindependent antigens in chickens. Poultry Sci 70:2371-2374

Nelson RJ, Demas GE (1996) Seasonal changes in immune function. Q Rev Biol 71:511-548

Norris K, Evans MR (2000) Ecological immunology: life-history trade-offs and immune defense in birds. Behav Ecol 11:19-26

Ots I, Kerimov AB, Ivankina EV, Ilyina TA, Horak P (2001) Immune challenge affects basal metabolic activity in wintering great tits. Proc R Soc Lond [Biol] 268:1175-1181

Palmer AR, Strobeck C (1986) Fluctuating asymmetry: measurement, analysis, patterns. Annu Rev Ecol Syst 17:391-421

Raberg L, Grahn M, Hasselquist D, Svensson E (1998) On the adaptive significance of stress-induced immunosuppression. Proc R Soc Lond [Biol] 265:1637-1641

Sanz JJ, Moreno J, Merino S, Tomas G (2004) A trade-off between two resource demanding functions: post-nuptial moult and immunity during reproduction in male pied flycatchers. J Anim Ecol 73:441-447

Schimid-Hempel P (2003) Variation in immune defence as a question of evolutionary ecology. Proc R Soc Lond [Biol] 269:357-366

Sheldon BC, Verhulst S (1996) Ecological immunology: costly parasite defences and trade-offs in evolutionary ecology. Trends Ecol Evol 11:317-321

Speakman JR (1997) Doubly labeled water: theory and practice. Chapman \& Hall, London

StatSoft Inc (2001) STATISTICA (data analysis software system), Version 6. StatSoft, Tulsa, Okla.

Svensson E, Raberg L, Koch C, Hasselquist D (1998) Energetic stress, immunosuppression, and the cost of an antibody response. Funct Ecol 12:912-919

Swaddle J (1996) Reproductive success and symmetry in zebra finches. Anim Behav 51:203-210

Thomas ALR (1993) The aerodynamic costs of asymmetry in the wings and tail in birds: asymmetric birds can't fly round tight corners. Proc R Soc Lond [Biol] 254:181-189

Van Valen L (1962) A study of fluctuating asymmetry. Evolution 16:125-142

Visser GH, Schekkerman H (1999) Validation of the doubly labeled water method in growing precocial birds: The importance of assumptions concerning evaporative water loss. Physiol Zool 72:740-749

Wakelin D (1997) Parasites and the immune system. Conflict or compromise? Bioscience 47:32-40

Webster MD, Weathers WW (1989) Validation of single-sample doubly labelled water method. Am J Physiol 256:R572-R576

Wegmann TG, Smithies O (1966) A simple hemagglutination system requiring small amounts of red cells and antibodies. Transfusion 6:67-73

Whitaker S, Fair J (2002) The costs of immunological challenge to developing mountain chickadees, Poecile gambeli, in the wild. Oikos 99:161-165

Wikelski M, Ricklefs R (2001) The physiology of life-histories. Trends Ecol Evol 16:479-481

Yorinks N, Atkinson CT (2000) Effects of malaria on activity budgets of experimentally infected juvenile apapane (Himatione sanguinea). Auk 117:731-738

Zuk M, Stoehr AM (2002) Immune defense and host life history. Am Nat 160:S9-S22 